\title{
DISTRIBUIÇÃO E FONTE DE RESÍDUOS SÓLIDOS AO LONGO DO ARCO PRAIAL DE JACONÉ-SAQUAREMA (RJ)
}

\section{Distribution and source of solid waste along the Jaconé-Saquarema (RJ) beach arc}

\author{
Lucas Ferreira Corrêa \\ Mestrando do Programa de Pós-Graduação em Geografia da UERJ-FFP \\ lucasferreira.geografia@gmail.com \\ André Luiz Carvalho da Silva \\ Professor Adjunto do Departamento de Geografia da UERJ-FFP \\ andrelcsilvageouerj@gmail.com
}

Ana Beatriz Pinheiro Doutoranda do Progr. de Pós-Graduação em Dinâmica dos Oceanos e da Terra da UFF ana.beatriz.geo@gmail.com

Valéria Cristina Silva Pinto Mestra pelo programa de pós-graduação em Geografia da UERJ-FFP cristina.valeria093@gmail.com

Andrea Viana Macedo Mestranda no programa de Pós-Graduação em Geografia da UERJ-FFP vmacedo.avm@gmail.com

Emanuelle Assunção Loureiro Madureira Mestranda no programa de Pós-Graduação em Geografia da UERJ-FFP manumadureira.uerj@gmail.com

Artigo enviado para publicação em 30/04/2019 e aceito em 11/06/2019

DOI: $10.12957 /$ tamoios.2019.42363

\section{Resumo}

Este estudo objetivou caracterizar os macro e micro resíduos sólidos no arco praial de JaconéSaquarema (RJ) quanto à distribuição, composição e fontes, para identificar a relação dos materiais encontrados com os diversos usos e a dinâmica costeira. A área de estudo, com 19 km de extensão, compreende os municípios de Maricá (oeste) e Saquarema (leste), respectivamente. Os monitoramentos foram realizados em cinco locais ao longo do arco praial, entre verão e inverno de 2018. Os macro resíduos foram identificados numa área de 25x50m; os microplásticos foram extraídos de sedimentos coletados na linha de deixa, numa área de 1x1m e 5cm de profundidade. Os resultados mostram que o lixo composto por plásticos é predominante. Verificou-se uma maior concentração no setor oeste da praia de Jaconé e no verão. Apesar do maior fluxo de turistas no setor leste, o lixo é recolhido com frequência, o que não ocorre nos demais locais. Nessas praias de mar aberto, o lixo se encontra em grande parte desgastado, devido ao retrabalhamento pela ação das ondas. Alguns materiais encontrados (como inseticidas, desodorante e baldes) não são descartados por frequentadores locais, mas trazidos pelas correntes marinhas. Verificou-se a presença de microplásticos nas praias estudadas, com destaque para as fibras, provenientes da degradação de outros materiais.

Palavras-chave: Jaconé-Saquarema, lixo marinho, praias, processos costeiros. 


\begin{abstract}
The present study aims to characterize the distribution, composition and sources of macro and micro solid wastes on the Jaconé and Saquarema (RJ) beaches, to identify the relationship between the materials found and the various uses and coastal dynamics. The study area, with $19 \mathrm{~km}$ of extension, comprises the municipalities of Maricá (west) and Saquarema (east), respectively. Monitoring was carried out at five sites along the beach arc between summer and winter of 2018. The macro residues were identified in an area of $25 \times 50 \mathrm{~m}$; the micro-plastics were extracted from sediments collected in the wrack line, in an area of $1 \times 1 \mathrm{~m}$ and $5 \mathrm{~cm}$ in depth. The results show that garbage composed of plastics is predominant. There was a greater concentration during the summer, in the western sector of Jaconé beach. Despite the greater influx of tourists in the eastern sector, garbage is collected frequently, which is not the case elsewhere. On these beaches of open sea, the garbage is largely worn, due to reworking by wave action. Some materials found (such as insecticides, deodorant and buckets) are not discarded by local regulars, but brought by the sea currents. The presence of microplastics was found on the studied beaches, especially that of fibers, due to the degradation of other materials.
\end{abstract}

Keywords: Jaconé-Saquarema, marine trash, beaches, coastal processes. 


\section{Introdução}

$\mathrm{O}$ arco praial de Jaconé-Saquarema está localizado respectivamente nos municípios de Maricá e Saquarema, no estado do Rio de Janeiro, com 19,5 km de extensão; limita-se a oeste pelo costão de Ponta Negra, e a leste pelo costão de Saquarema (Figura 1). Este litoral apresenta grande importância turística e abrange diferentes colônias de pescadores artesanais; conta com a presença dos beachrocks de Jaconé, de grande importância geológica, histórica e arqueológica na região (MANSUR et al., 2011). A ocupação deste litoral tem promovido a descaracterização desses ambientes e causado problemas decorrentes do descarte irregular de materiais ao longo do arco praial. Essa situação é preocupante, principalmente quando se considera a rica biodiversidade deste litoral e demais áreas costeiras e marinhas do litoral fluminense, assim como a importância das atividades ligadas ao turismo e a pesca para a população nessas áreas. Neste sentido, este estudo objetiva caracterizar a distribuição e fonte dos resíduos sólidos (incluindo os microplásticos) encontrados ao longo do arco praial Jaconé-Saquarema. Almejou-se também analisar o papel dos processos costeiros no transporte e deposição dos materiais encontrados nas praias por ocasião dos monitoramentos, e a relação destes com as diversas atividades desenvolvidas na área de estudo e adjacências.

Este cenário chama atenção para a necessidade do desenvolvimento de pesquisas voltadas para a preservação deste ambiente, que abriga um conjunto de ecossistemas de elevada complexidade e importância no litoral fluminense. Desta forma, compreender os impactos causados por resíduos sólidos nas praias de Jaconé e Saquarema (Figura 1), a origem desses materiais e a relação com os processos responsáveis pela dinâmica neste litoral é fundamental para a elaboração de medidas voltadas para o planejamento e gestão das diferentes formas de uso e ocupação neste ambiente. Os impactos decorrentes das diferentes formas de poluição tendem a comprometer o equilíbrio dos ecossistemas marinhos e costeiros, além de oferecer risco para a saúde dos banhistas e prejudicar diretamente as atividades essenciais à economia local (SANTOS et al., 2008; FARIAS, 2012). Essa questão passou a ser tratada com maior relevância após a publicação da lei n ${ }^{\circ} 12.305$ de 02 de agosto de 2010, quando o tema poluição por resíduos sólidos passou a ser cada vez mais abordado na mídia, nas pesquisas científicas e em programas de educação ambiental. Coe e Rogers (1997) define lixo como sendo qualquer resíduo sólido de origem humana que foi inserido no ambiente marinho pela ação antrópica. De acordo com Somerville et al. (2003), os resíduos sólidos podem ser provenientes de quatro fontes principais: (1) turismo e atividades recreativas, (2) atividades pesqueiras, (3) esgotos e (4) navegação. Todas essas fontes de lixo estão diretamente condicionadas à relação entre o aumento da produção e do consumo mundial e a falta de preocupação com o descarte destes rejeitos produzidos pelas diversas sociedades.

Entre os resíduos sólidos, os plásticos estão entre os materiais que mais predominam nos ambientes costeiros e marinhos (COE e ROGERS, 1997; UNEP, 2005; BAPTISTA NETO e FONSECA, 2011). Sua maleabilidade, durabilidade e baixo custo explicam a grande adesão mundial do material na fabricação de produtos de diversos gêneros (LAIST, 1987), porém oferecem sérios riscos para o meio ambiente (PRUTER, 1987; LAIST, 1987). A proporção de lixo composto por plástico nos oceanos aumenta com a distância em relação às áreas de origem, pois são mais facilmente transportados que os materiais mais densos (como os vidros e metais); também, porque possuem um tempo maior para a decomposição quando comparado a outros materiais de baixa densidade (como papel e tecidos) (RYAN et al., 2009). Os detritos plásticos flutuantes têm se tornado um problema global crescente, pois são 
transportados por longas distâncias através das bacias oceânicas, alcançando até mesmo as ilhas mais remotas (BARNES, 2002). Muitos detritos plásticos estão presentes nos oceanos na forma de pequenas partículas, o que representa uma ameaça potencial devido ao pequeno tamanho (microplásticos) e o longo tempo de degradação destes materiais. Os animais marinhos são os mais impactados com os microplásticos e morrem em grande parte por inanição, uma vez que ingerem microplásticos por confundirem com alimentos, entre outras causas (LAIST, 1997; FISNER et al., 2013). O método escolhido para o monitoramento dos resíduos sólidos deve considerar as particularidades de cada localidade, assim como, os objetivos a serem alcançados. O monitoramento do lixo marinho pode ser realizado de três formas: amostragem no fundo e na superfície oceânica, e nas áreas costeiras (SANTOS et al., 2008). Essa última forma foi empregada neste estudo por ser a de mais baixo custo e, consequentemente, de ampla utilização em estudos dessa natureza, conforme ressaltado por Baptista Neto e Fonseca (2011).

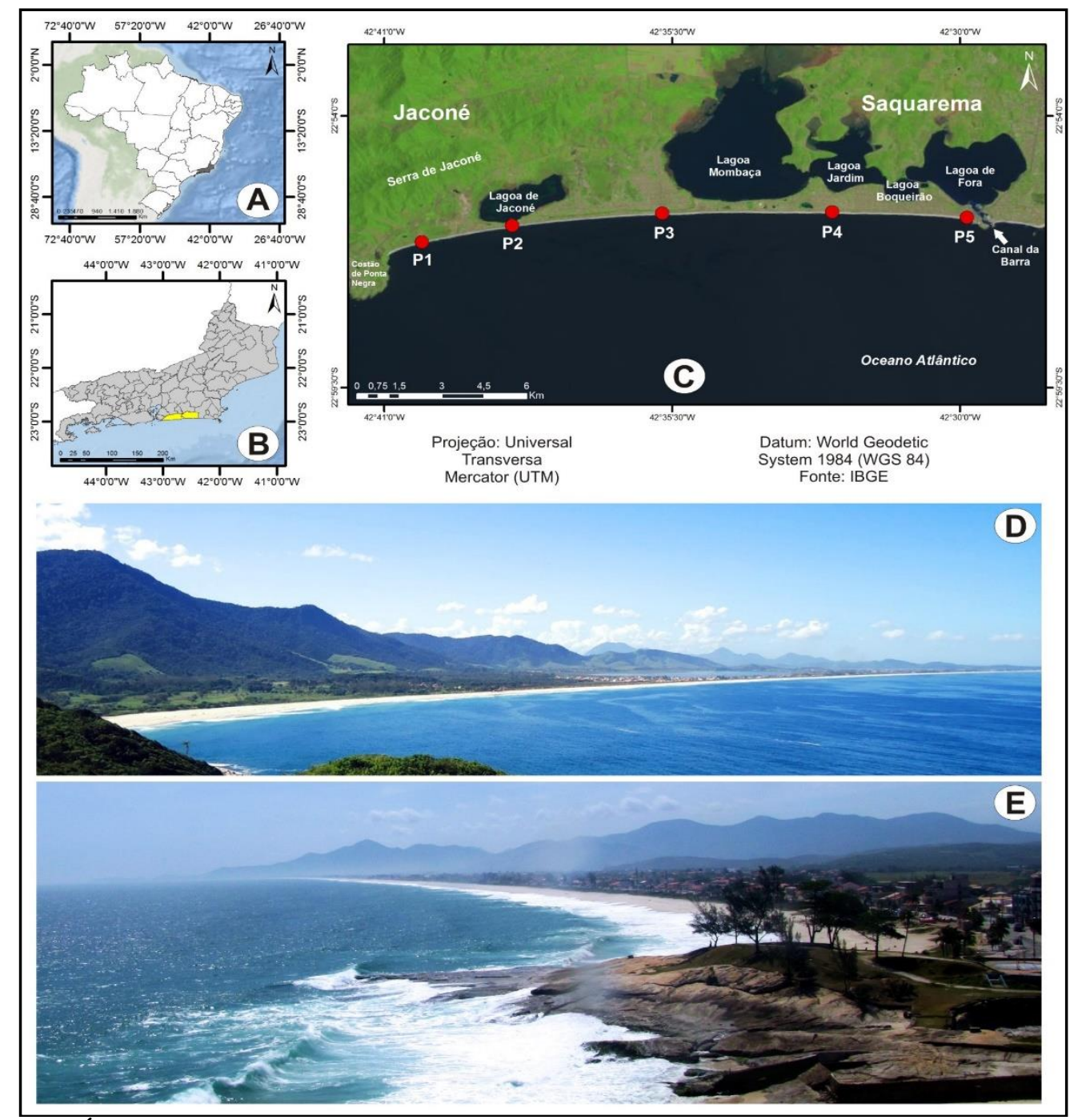

Figura 1 - Área de estudo: litoral de Jaconé (D) e Saquarema (E). Fotos: D, Fernando Silva (2012); E, André Silva (2014). 


\section{Área de estudo}

O arco praial de Jaconé-Saquarema (Figura 1) possui cerca de 19 quilômetros de extensão, com orientação leste-oeste; e está localizado na Região das Baixadas Litorâneas, cerca de 49 quilômetros a leste da entrada da Baía de Guanabara. O litoral de JaconéSaquarema (Figura 1D e E, respectivamente) apresenta uma rica biodiversidade, mais facilmente observada em Jaconé, onde a quantidade de áreas desprovidas de construções é maior quando comparada a Saquarema. É marcante a presença da vegetação de restinga nas áreas de planície costeira, Mata Atlântica nos morros e na Serra de Jaconé (Figura 1D), além de diversas espécies de aves, mamíferos, répteis e peixes (BIAZZI E TONELLO, 2014; COSTA et al., 2016; DOS SANTOS et al., 2016). A atividade turística e o crescimento imobiliário são mais preocupantes na parte central e leste do arco praial e vêm causando fortes mudanças na região (HERCULANO, 1981).

A geomorfologia deste litoral se caracteriza pela presença de barreiras arenosas associadas a uma série de lagunas costeiras a retaguarda, conectadas ao mar através do canal localizado no extremo leste em Saquarema (Figura 1C). Essa geomorfologia se assemelha à de áreas adjacentes, que compreendem os litorais do Rio de Janeiro, Niterói, Maricá e Araruama (MAIA et al., 1984; IRELAND, 1987; TURCQ et al., 1999; PEREIRA et al., 2003; SILVA, 2011; SILVA et al., 2014a; SILVA et al., 2014c; SILVESTRE et al., 2017; entre outros). A evolução da planície costeira neste trecho do litoral fluminense ocorreu a partir do afogamento de áreas topograficamente mais baixas durante eventos de subida do nível do mar, com concomitante formação das barreiras arenosas e lagoas, tornando a linha de costa mais retilínea (PERRIN, 1984; COE NETO et al., 1986; IRELAND, 1987; MUEHE, 1989; TURCQ et al., 1999; PEREIRA et al., 2003; SILVA, 2011; SILVA et al., 2014a; SILVA et al., 2014b). Os beachrocks, localizados na zona de intermaré em Jaconé (Figura 2A), constituem-se num patrimônio geológico da região, pela sua grande importância histórica, arqueológica e geológica. Essas formações rochosas estão localizadas no setor oeste do arco praial, estendendo-se por cerca de 1.100 metros ao longo do litoral, e foram identificadas pela primeira vez pelo naturalista Charles Darwin em 1832. Pesquisas arqueológicas realizadas neste litoral indicam que os fragmentos do arenito de Jaconé encontrados em sambaquis eram utilizados pelo Homem Pré-histórico há mais de 4000 anos A.P. (MANSUR et al., 2011). Trata-se de um conjunto de rochas localizadas paralelamente à linha d'água na zona de intermaré da praia (MANSUR et al., 2011). Atualmente, este patrimônio da humanidade encontra-se ameaçado pelas inúmeras mudanças decorrentes da implantação do Complexo Portuário no setor oeste do litoral de Jaconé.

$\mathrm{Na}$ área de estudo os ventos são predominantes dos quadrantes leste e nordeste; quando da passagem de frentes frias os ventos provenientes do quadrante sudoeste são mais comuns e em geral de maior intensidade (CONCREMAT, 2011). A incidência de ondas provenientes de sul e de sudeste predomina durante condições de tempo bom; grandes ondas de tempestades aparecem associadas às ressacas oriundas dos quadrantes sul e, principalmente, sudoeste (Figura 2B). Durante as ressacas de maior magnitude, causadas por frentes frias ou ciclones extratropicais, essas ondas podem atingir o limite interno da praia e formar escarpas de tempestade, ou mesmo alcançar a porção superior e a retaguarda da barreira pelo processo de sobrelavagem (overwash) (Figura 2C) (SILVA et al., 2008b; PINTO et al., 2015; PINTO, 2018; LINS-DE-BARROS, 2017). Essas ondas são capazes de causar grandes variações na morfologia e na largura das praias (PINTO et al., 2015; PINTO, 2018). 
O arco praial Jaconé-Saquarema é marcada por uma dinâmica distinta causada pelas mudanças na energia das ondas que incidem no litoral e devido à presença do costão rochoso que parece contribuir para a convergência de ondas de tempestades no setor oeste (PINTO et al., 2015; PINTO, 2018). A incidência de grandes ondas de tempestades, que podem atingir mais de 3 metros na arrebentação, tende a provocar grande variabilidade na largura e morfologia da praia (Figura 2D); que também exibe uma boa recuperação após os eventos de ressaca, apontando para a estabilidade deste ambiente. A destruição de estruturas urbanas ao longo do litoral, em decorrência de eventos de tempestades de grande magnitude, é algo recorrente na área de estudo; e apontam para a vulnerabilidade deste trecho costeiro a eventos de tempestades (PINTO, 2018). Os sedimentos que compõem essas praias são constituídos predominantemente por areias quartzosas arredondadas e apresentam diminuição no tamanho dos grãos de oeste para leste, variando de areia muito grossa a média, respectivamente (FARIA 2014; PINTO et al., 2015; PINTO, 2018).

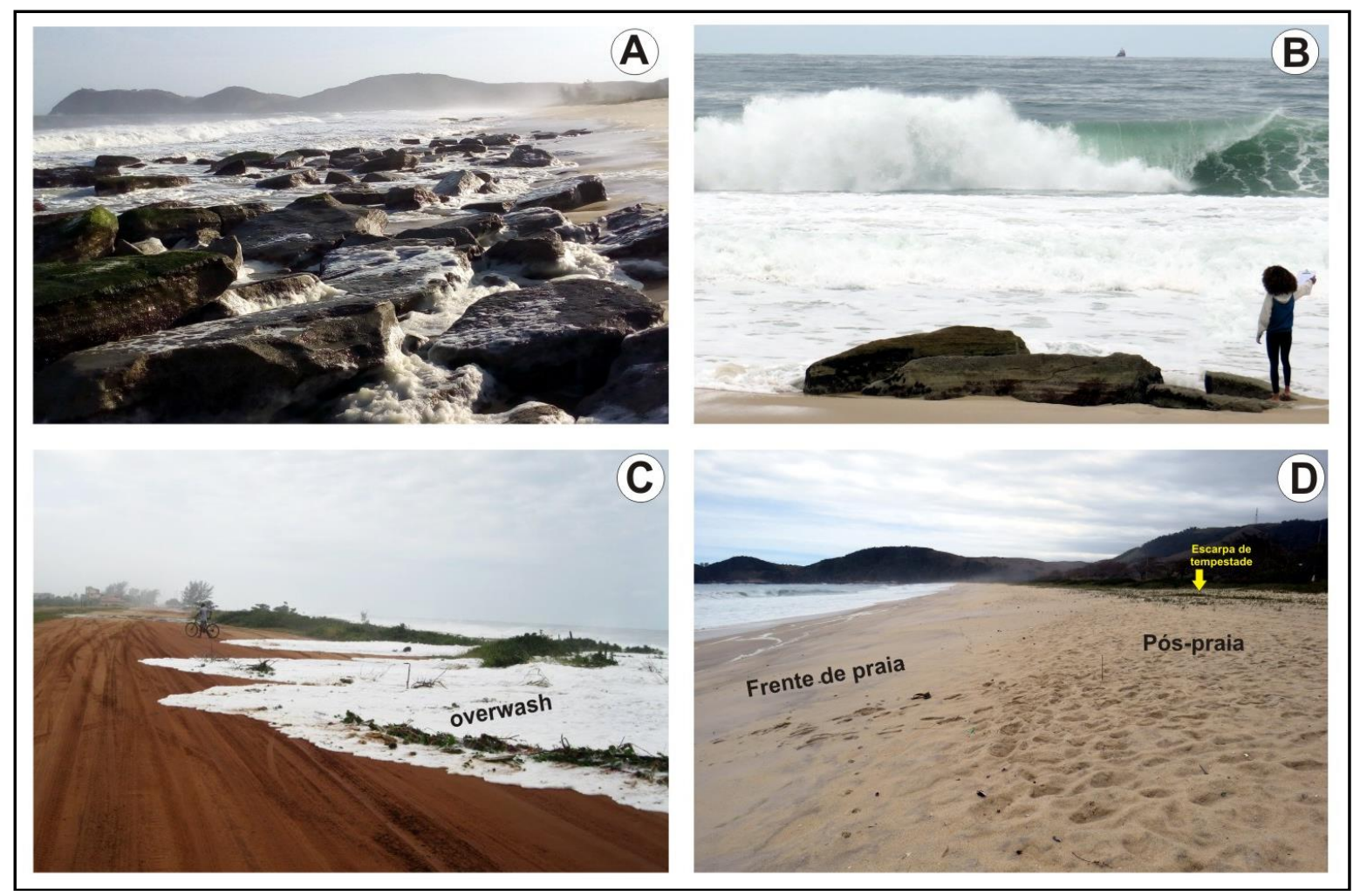

Figura 2 - Litoral de Jaconé-Saquarema: beachrocks na zona de intermaré (A); ondas de tempestades (B); processo de sobrelavagem (overwash), durante uma forte ressaca ocorrida em 2011 (C); morfologia da praia (D). Fotos: A e B, Valéria Pinto (2017); C, Fala Jaconé (2011); e D, André Silva (2017).

\section{Materiais e métodos}

O desenvolvimento do presente estudo constou das seguintes etapas: (1) trabalhos de campo, para a contagem e classificação dos macro resíduos presentes nas praias; (2) análise laboratorial para a extração e classificação dos microplásticos encontrados nas areias das praias estudadas. 
Foram realizados 2 trabalhos de campo (verão e inverno de 2018) ao longo de 5 locais de monitoramento (Figura 1C), definidos com base na extensão do arco praial e nas diferentes formas de uso e ocupação de cada praia estudada. No pós-praia foi demarcada uma área de 25x50m para a contagem e classificação dos macro resíduos sólidos (BAPTISTA NETO e FONSECA, 2011; MACEDO et al., 2017; MADUREIRA et al., 2017). A amostragem de sedimentos para a identificação de microplásticos ocorreu na linha de deixa correspondente a maré alta de sizígia, em uma área de $1 \mathrm{~m}^{2}$ e com $5 \mathrm{~cm}$ de profundidade, conforme Carvalho e Baptista Neto (2016). Os macro resíduos encontrados nas praias estudadas foram devidamente identificados, contados, catalogados e fotografados, para posterior caracterização dos materiais e verificação do estado de preservação destes, necessário para se entender a relação entre a origem (local ou externa) e a distribuição. Os resultados foram processados no software Microsoft Excel para a confecção de gráficos e tabelas, contendo a quantidade, o tipo de material encontrado e demais informações.

No laboratório, a análise dos micro resíduos constou das seguintes etapas: (1) extração de microplásticos nas areias das praias; (2) contagem e classificação na lupa binocular. A extração de microplásticos consistiu: na pesagem inicial das amostras; secagem na estufa a $60^{\circ} \mathrm{C}$ por cerca de 24 horas; pesagem da amostra seca; peneiramento para a remoção de materiais com diâmetro superior à 5mm (GREGORY, 1977); preparação da solução hipersalina $(358,9 \mathrm{~g}$ de $\mathrm{NaCl}$ para cada litro de água); agitação da amostra por 5 minutos; decantação dos sedimentos por 5 horas; remoção do material flutuante; filtragem com bomba à vácuo (5CFM); secagem dos filtros na estufa por 72 horas (THOMPSON et al., 2004; BESLEY et al., 2016). A contagem e classificação de microplásticos foi realizada na lupa binocular, com o auxílio do software ToupView para a análise digital dos mesmos. Foi adotada a classificação proposta por Carvalho e Batista Neto (2016).

\section{Resultados}

\section{Resíduos sólidos nas praias de Jaconé e Saquarema}

O monitoramento realizado no verão de 2018 permitiu constatar a presença de diferentes tipos de resíduos sólidos nas praias de Jaconé e Saquarema, com destaque para o setor oeste do arco praial, que apresentou a maior concentração de materiais (Tabela 1, Figura 3). No extremo oeste do arco praial de Jaconé (área do P1; Figura 1C), a quantidade de resíduos sólidos encontrados no pós-praia correspondeu a 402 itens (Tabela 1, Figura 3); com o predomínio de objetos compostos por plásticos (339 unidades), seguidos por madeira (27), metais diversos (8), restos de construção (7), corda (5), isopor (5), fezes de animais (4), cigarro (2), nylon (2), lata (1), borracha (1) e vidro (1) (Tabela 1, Figuras 4 e 5). No setor oeste do arco praial (P2; Figura 1C), foram identificados um total de 347 resíduos sólidos (Tabela 1, Figura 3); quantidade ligeiramente menor que o encontrado no extremo oeste (P1) do arco praial. Dentre os materiais identificados na área do P2 (Figura 1C), o plástico (260 unidades) se constitui no tipo de material predominante na composição do lixo presente na praia; acompanhado de carvão (30), metal (24), madeira (12), corda (5), restos de construção (4), papel/papelão (4), lata (2), borracha (2), nylon (2), tecido (1) e isopor (1) (Tabela 1, Figuras 4 e 5). No meio do arco praial de Jaconé-Saquarema (P3; Figura 1C), os resíduos sólidos encontrados na praia representam um total de 86 itens (Tabela 1, Figura 3); quantidade extremamente menor que a observada nas áreas monitoradas no extremo oeste (P1) e oeste (P2) do arco de praia, que exibiram 402 e 347 itens, respectivamente (Tabela 1, 
Figura 3). Os materiais compostos por plástico, assim como nas demais áreas, são predominantes e correspondem a um total de 49 itens; seguido por cigarro (19), isopor (9), madeira (4), metal (3), papel/papelão (1) e lata (1) (Tabela 1, Figuras 4 e 5). No setor leste do arco praial de Saquarema (P4; Figura 1C), a quantidade de resíduos sólidos depositados no pós-praia foi de apenas 36 unidades (Tabela 1, Figura 3), sendo, portanto, a menor quantidade verificada ao longo de toda a área de estudo. Dentre os materiais encontrados, os plásticos permanecem predominantes (21 unidades); seguido de cigarro (8), corda (2), isopor (2), madeira modificada (2) e nylon (1) (Tabela 1, Figuras 4 e 5). A redução do quantitativo de resíduos sólidos encontrados neste ponto de monitoramento pode estar relacionada à limpeza da praia, que ocorre com regularidade a partir deste setor do litoral, que se encontra mais urbanizado em comparação com as demais áreas em direção a oeste (Jaconé). No extremo leste da área de estudo (P5; Figura 1C), localizado próximo à igreja Nossa Senhora de Nazareth (trecho mais urbanizado do arco praial), pode-se identificar a presença de resíduos sólidos como garrafas pets, redes de pesca, restos de embalagens de comidas, entre outros objetos, que juntos somam 161 itens (Tabela 1, Figura 3). O lixo composto por plástico (112 unidades) predomina, assim como nas demais áreas monitoradas; cigarro (12), madeira (12), metal (12), papel/papelão (8), carvão (2), resto de construção (1), isopor (1) e tecido (1), aparecem em menor quantidade entre os materiais encontrados neste setor de Saquarema (Tabela 1, Figuras 4 e 5).

Tabela 1 - Quantidade e composição dos resíduos sólidos em Jaconé-Saquarema.

\begin{tabular}{|c|c|c|c|c|c|c|c|c|c|c|c|c|}
\hline \multirow{3}{*}{$\begin{array}{l}\text { Composição dos } \\
\text { Resíduos Sólidos }\end{array}$} & \multicolumn{6}{|c|}{ Praia de Jaconé } & \multicolumn{4}{|c|}{ Praia de Saquarema } & \multirow{3}{*}{$\begin{array}{l}\text { Total de } \\
\text { verão }\end{array}$} & \multirow{3}{*}{$\begin{array}{l}\text { Total de } \\
\text { inverno }\end{array}$} \\
\hline & \multicolumn{3}{|c|}{ Verão } & \multicolumn{3}{|c|}{ Inverno } & \multicolumn{2}{|c|}{ Verão } & \multicolumn{2}{|c|}{ Inverno } & & \\
\hline & P1 & P2 & P3 & P1 & $\mathbf{P 2}$ & P3 & P4 & P5 & P4 & P5 & & \\
\hline Plásticos & 339 & 260 & 49 & 44 & 140 & 281 & 21 & 112 & 62 & 568 & 781 & 1095 \\
\hline Vidro & 1 & 0 & 0 & 0 & 1 & 2 & 0 & 0 & 0 & 2 & 1 & 5 \\
\hline Papel/papelão & 0 & 4 & 1 & 0 & 0 & 4 & 0 & 8 & 1 & 0 & 13 & 5 \\
\hline Madeira modificada & 27 & 12 & 4 & 0 & 0 & 1 & 2 & 12 & 4 & 13 & 57 & 18 \\
\hline Metais diversos & 8 & 24 & 3 & 0 & 5 & 2 & 0 & 12 & 2 & 2 & 47 & 11 \\
\hline Matéria orgânica & 0 & 0 & 0 & 15 & 0 & 79 & 0 & 0 & 0 & 1 & 0 & 95 \\
\hline Fezes de animais & 4 & 0 & 0 & 0 & 0 & 0 & 0 & 0 & 0 & 0 & 4 & 0 \\
\hline Lata & 1 & 2 & 1 & 0 & 0 & 0 & 0 & 0 & 0 & 0 & 4 & 0 \\
\hline Borracha & 1 & 2 & 0 & 0 & 2 & 3 & 0 & 0 & 3 & 3 & 3 & 11 \\
\hline Isopor & 5 & 1 & 9 & 5 & 35 & 92 & 2 & 1 & 34 & 0 & 18 & 166 \\
\hline Tecido & 0 & 1 & 0 & 0 & 0 & 1 & 0 & 1 & 2 & 1 & 2 & 4 \\
\hline Nylon & 2 & 2 & 0 & 0 & 1 & 1 & 1 & 0 & 0 & 5 & 5 & 7 \\
\hline Corda & 5 & 5 & 0 & 0 & 1 & 0 & 2 & 0 & 1 & 1 & 12 & 3 \\
\hline Cigarro & 2 & 0 & 19 & 0 & 0 & 9 & 8 & 12 & 0 & 0 & 41 & 9 \\
\hline Restos de construção & 7 & 4 & 0 & 3 & 0 & 30 & 0 & 1 & 0 & 0 & 12 & 33 \\
\hline Fralda descartável & 0 & 0 & 0 & 0 & 0 & 0 & 0 & 0 & 0 & 0 & 0 & 0 \\
\hline Espuma & 0 & 0 & 0 & 0 & 0 & 5 & 0 & 0 & 1 & 0 & 0 & 6 \\
\hline Ferro & 0 & 0 & 0 & 0 & 0 & 0 & 0 & 0 & 0 & 0 & 0 & 0 \\
\hline Cerâmica & 0 & 0 & 0 & 0 & 0 & 0 & 0 & 0 & 0 & 0 & 0 & 0 \\
\hline Carvão & 0 & 30 & 0 & 0 & 0 & 0 & 0 & 2 & 0 & 0 & 32 & 0 \\
\hline Total & 402 & 347 & 86 & 67 & 185 & 510 & 36 & 161 & 110 & 596 & 1032 & 1468 \\
\hline
\end{tabular}

O monitoramento realizado no inverno de 2018 permitiu constatar a existência de uma menor concentração de resíduos sólidos no setor oeste da área de estudo (P1 e P2; Figura 1C), contrastando com os dados obtidos no verão do mesmo ano, onde este trecho apresentou a maior concentração de resíduos sólidos (Tabela 1, Figura 3). No extremo oeste do arco praial de Jaconé-Saquarema (P1; Figura 1C), a quantidade de resíduos sólidos depositados no pós-praia corresponde a um total de 67 unidades (Tabela 1, Figura 3); sendo a maior parte representada por objetos compostos por plástico (44 unidades); seguido por matéria orgânica (15), isopor (5) e restos de construção (3) (Tabela 1, Figuras 4 e 5). No setor oeste da praia de Jaconé (P2; Figura 1C) foram identificados 185 itens na faixa de areia emersa da praia 
(Tabela 1, Figura 3). Essa quantidade representa cerca da metade de todo o material identificado neste mesmo setor no verão do mesmo ano (Tabela 1, Figura 3). Entre os materiais encontrados, o plástico predominou com 140 unidades; em seguida, destacaramse: isopor (35), metal (5), borracha (2), corda (1), nylon (1) e vidro (1) (Tabela 1, Figura 3). No meio do arco praial (P3; Figura 1C), os resíduos sólidos identificados no pós-praia correspondem a 510 unidades (Tabela 1, Figura 3). Este valor é quase seis vezes maior que o registrado no verão do mesmo ano (Tabela 1, Figura 3). Esse aumento expressivo pode ser o resultado de um acúmulo de lixo pela ação das ondas de tempestades, mais frequentes neste litoral durante o inverno, conforme relatado por Pinto (2018). Também pode ser o resultado de um descarte irregular de lixo na praia por moradores das redondezas. Cabe destacar que o sistema de coleta de lixo no município é precário em algumas áreas e eventualmente interrompido por diversas razões. Os plásticos representam 281 itens; seguidos em menor quantidade por: isopor (92), matéria orgânica (79), restos de construção (30), cigarro (9), espuma (5), papel/papelão (4), borracha (3), vidro (2), metal (2), madeira (1), tecido (1) e nylon (1) (Tabela 1, Figura 3). Neste mesmo setor da praia foram encontradas seringas usadas com agulhas (Figura 4, Perfil 3B), o que representa um risco potencial para os frequentadores. Materiais cortantes e perfurantes, como lâminas, vidros, pregos e agulhas, foram encontrados também na praia do Abraão na Ilha Grande (Angra dos Reis, RJ) por Macedo et al. (2017), que atribui a presença desses materiais ao descarte inadequado por frequentadores locais. No setor leste do arco praial (P4; Figura 1C) em Saquarema, a quantidade de resíduos sólidos depositados no pós-praia correspondem a 110 unidades (Tabela 1, Figura 3). Este número é três vezes maior que o verificado no verão. Entre os materiais encontrados, os objetos compostos por plásticos são predominantes, com 62 unidades; em menor quantidade foram identificados isopor (34), madeira (4), borracha (3), metal (2), tecido (2) e corda (1), espuma (1) e papel/papelão (1) (Tabela 1, Figuras 4 e 5). No extremo leste (P5; Figura 1C), identificou-se a presença de 596 resíduos sólidos na areia da praia; número bastante elevado em relação ao verificado no verão de 2018 (Tabela 1, Figura 3). A quase totalidade dos resíduos sólidos presentes na praia é representada por plástico, totalizando 568 unidades; os demais materiais aparecem em menor quantidade e são representados por: madeira (13), nylon (5), borracha (3), metal (2), vidro (2), corda (1), matéria orgânica (1) e tecido (1) (Tabela 1, Figuras 4 e 5). 


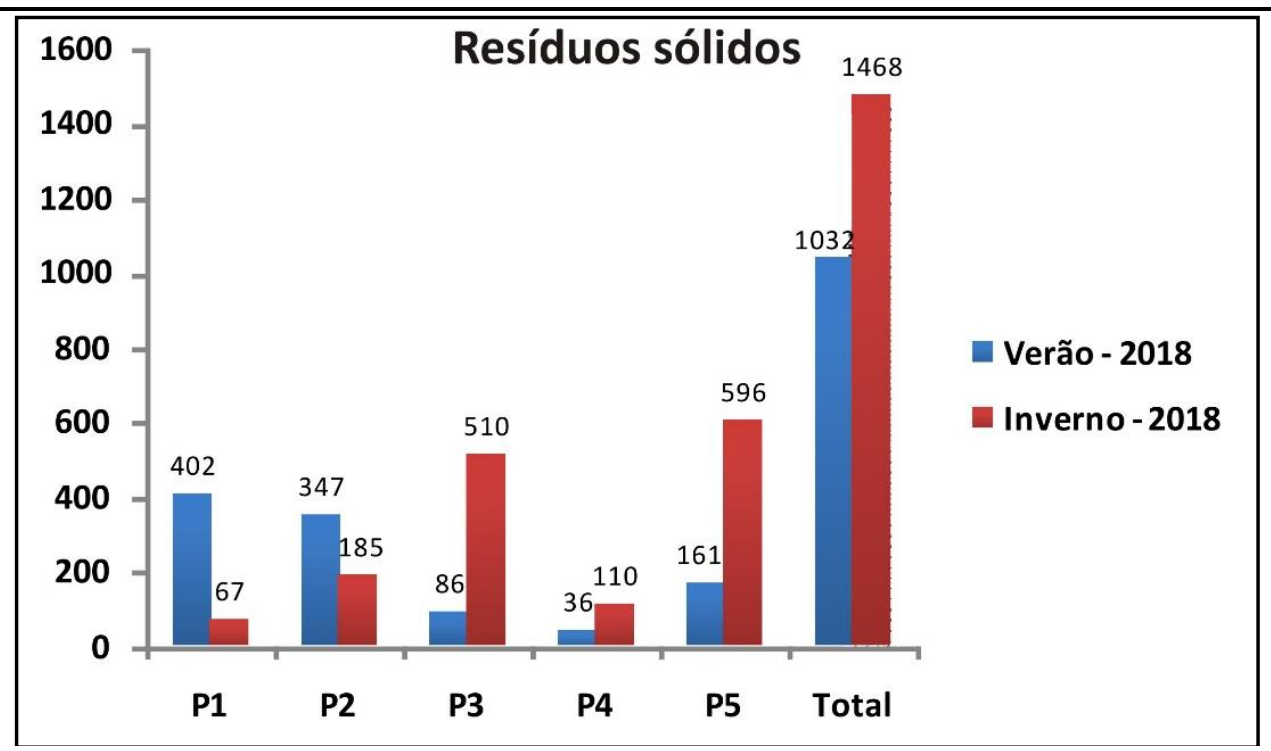

Figura 3 - Distribuição dos resíduos sólidos ao longo do litoral de Jaconé-Saquarema no verão e inverno de 2018.

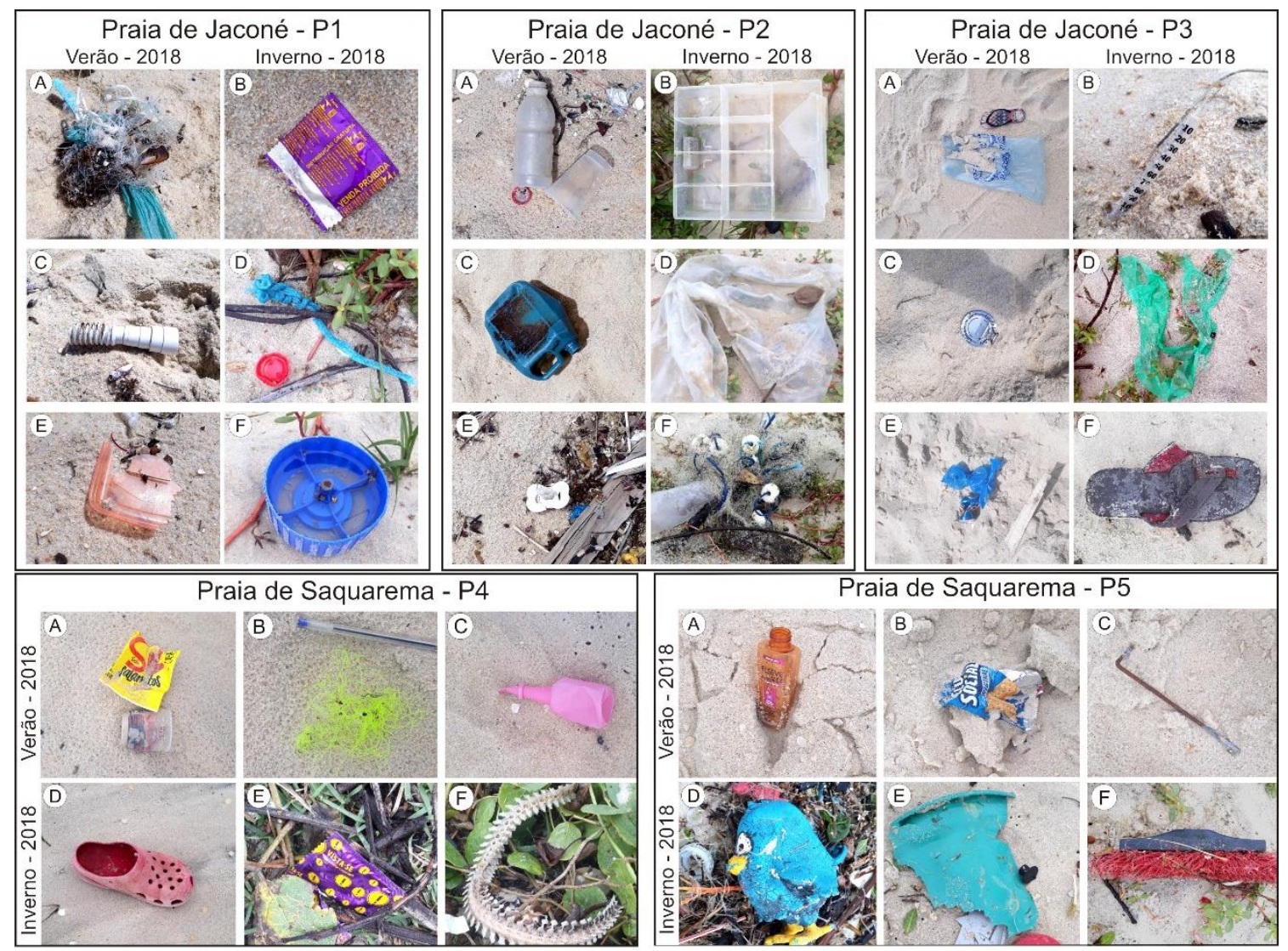

Figura 4 - Resíduos sólidos identificados ao longo de todo o arco praial nas estações de verão e inverno do ano de 2018. 


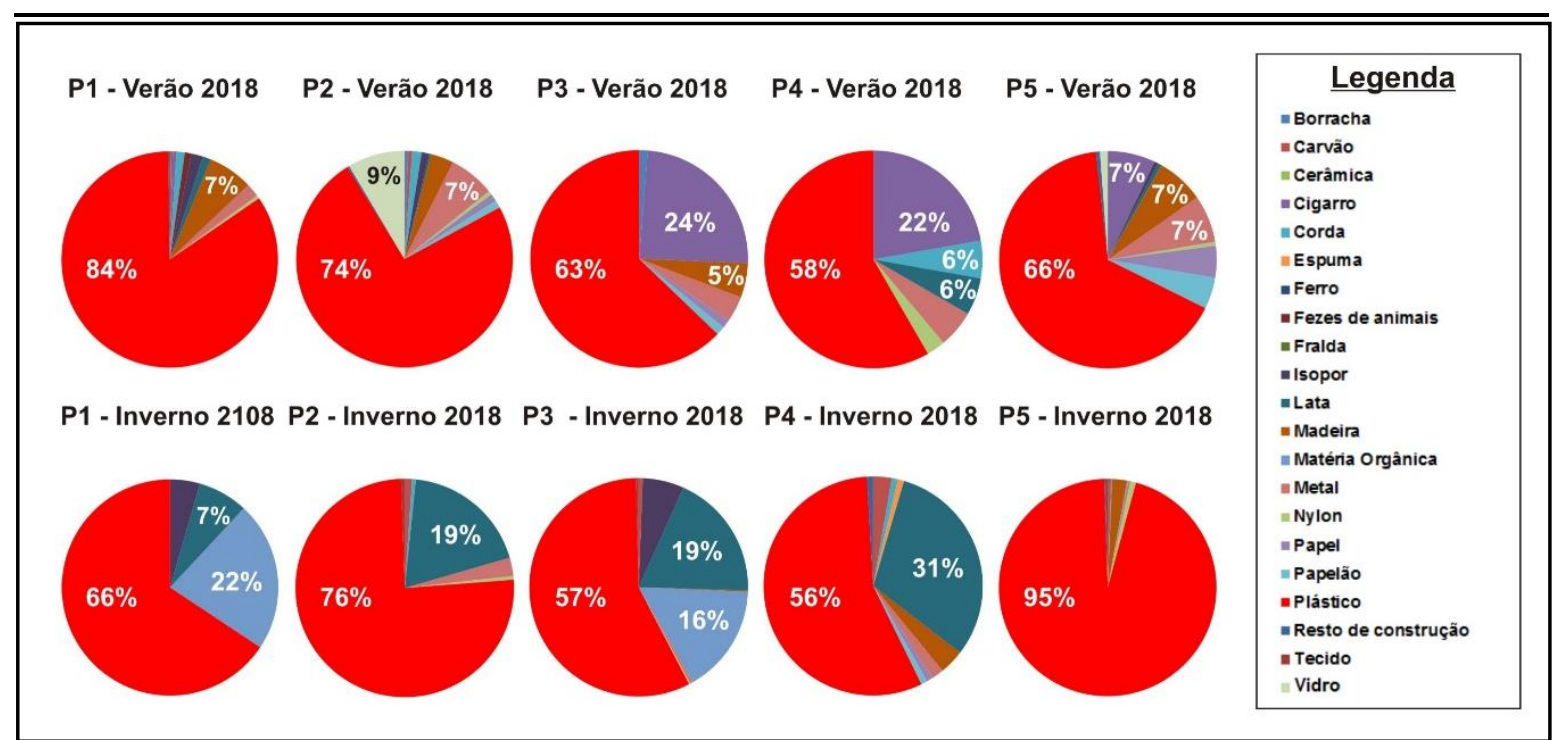

Figura 5 - Porcentagem dos tipos de resíduos sólidos encontrados no arco praial de JaconéSaquarema.

\section{Presença de microplásticos nas areias das praias}

Os microplásticos foram encontrados ao longo de todo o arco praial nos dois monitoramentos (Tabela 2, Figuras 6 e 7). Neste estudo, os resíduos sólidos classificados como microplásticos apresentam, em geral, diâmetro inferior a $5 \mathrm{~mm}$, conforme Browne (2007).

No verão de 2018 foi encontrado no extremo oeste do arco praial de Jaconé (P1; Figura 1C) 27 itens de microplásticos; sendo a quase totalidade representado por fibras (26); seguida por fragmento (1) (Tabela 2, Figuras 6 e 7). No setor oeste do arco praial (P2; Figura 1C) foram identificados um total de 24 micro resíduos plásticos na região do pós-praia, com a predominância de fibras (23 unidades), seguido de fragmento (1) (Tabela 2, Figuras 6 e 7). No meio do arco praial (P3; Figura 1C), os microplásticos encontrados totalizaram 19 unidades, sendo todas representadas por fibra (Tabela 2, Figuras 6 e 7). O setor leste (P4; Figura 1C) na praia de Saquarema apresentou apenas 15 unidades de microplásticos do tipo fibra (Tabela 2, Figuras 6 e 7). No extremo leste da área de estudo (P5; Figura 1C), constatouse a presença de 39 itens de microplásticos, todos representados por fibra (Tabela 2, Figuras 6 e 7$)$.

Tabela 2 - Microplásticos identificados nos sedimentos das praias de Jaconé e Saquarema.

\begin{tabular}{|c|c|c|c|c|c|c|c|}
\hline & & Setor & Fibra & Fragmento & Poliestireno & Pellet & Total \\
\hline & \multirow{5}{*}{$\frac{\infty}{\stackrel{\sim}{\vec{\nu}}}$} & P1 & 26 & 1 & 0 & 0 & 27 \\
\hline & & P2 & 23 & 1 & 0 & 0 & 24 \\
\hline & & P3 & 19 & 0 & 0 & 0 & 19 \\
\hline & & $\mathrm{P} 4$ & 15 & 0 & 0 & 0 & 15 \\
\hline & & P5 & 39 & 0 & 0 & 0 & 39 \\
\hline \multirow{5}{*}{ 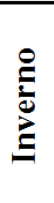 } & \multirow{5}{*}{$\frac{\infty}{\vec{\sim}}$} & P1 & 12 & 1 & 0 & 0 & 13 \\
\hline & & P2 & 15 & 1 & 0 & 0 & 15 \\
\hline & & P3 & 21 & 0 & 0 & 0 & 21 \\
\hline & & $\mathrm{P} 4$ & 15 & 1 & 0 & 0 & 16 \\
\hline & & P5 & 22 & 0 & 1 & 0 & 23 \\
\hline
\end{tabular}


No inverno de 2018, pode-se perceber uma redução na quantidade de microplásticos encontrados ao longo de quase toda a extensão do arco praial de Jaconé-Saquarema, em comparação com o verão do mesmo ano (Tabela 2, Figuras 6 e 7). No inverno de 2018, observou-se um maior acúmulo dessas micro partículas no setor oeste (Tabela 2, Figuras 6 e 7). Tal como no verão, a fibra também representou o item mais encontrado ao longo dos pontos de monitoramento (Tabela 2, Figuras 6 e 7). No extremo oeste do arco praial de Jaconé (P1; Figura 1C), os microplásticos correspondem a 13 unidades, compostos por fibras (12) e fragmento (1) (Tabela 2, Figuras 6 e 7). No setor oeste (P2; Figura 1C) foram encontrados 16 microplásticos, representados em grande parte por fibra (15) e fragmento (1) (Tabela 2, Figuras 6 e 7). No meio do arco praial (P3; Figura 1C), a quantidade de microplásticos identificados correspondeu a 21 unidades, sendo todos eles compostos por fibra (Tabela 2, Figuras 6 e 7). No setor leste e extremo leste do arco praial (P4 e P5, respectivamente; Figura 1C) em Saquarema, a quantidade de microplásticos encontrados no pós-praia foi de 39 unidades, apresentando uma redução referente aos mesmos locais na estação de verão, que apresentou 54 unidades (Tabela 2, Figuras 6 e 7). No P4 foram identificados 16 itens, sendo em sua maioria compostos por fibra (15), seguido de fragmento (1); no extremo leste (P5) foram encontrados um total de 23 microplásticos, sendo em sua maioria fibra (22 unidades), acompanhado de poliestireno (1) (Tabela 2, Figuras 6 e 7).

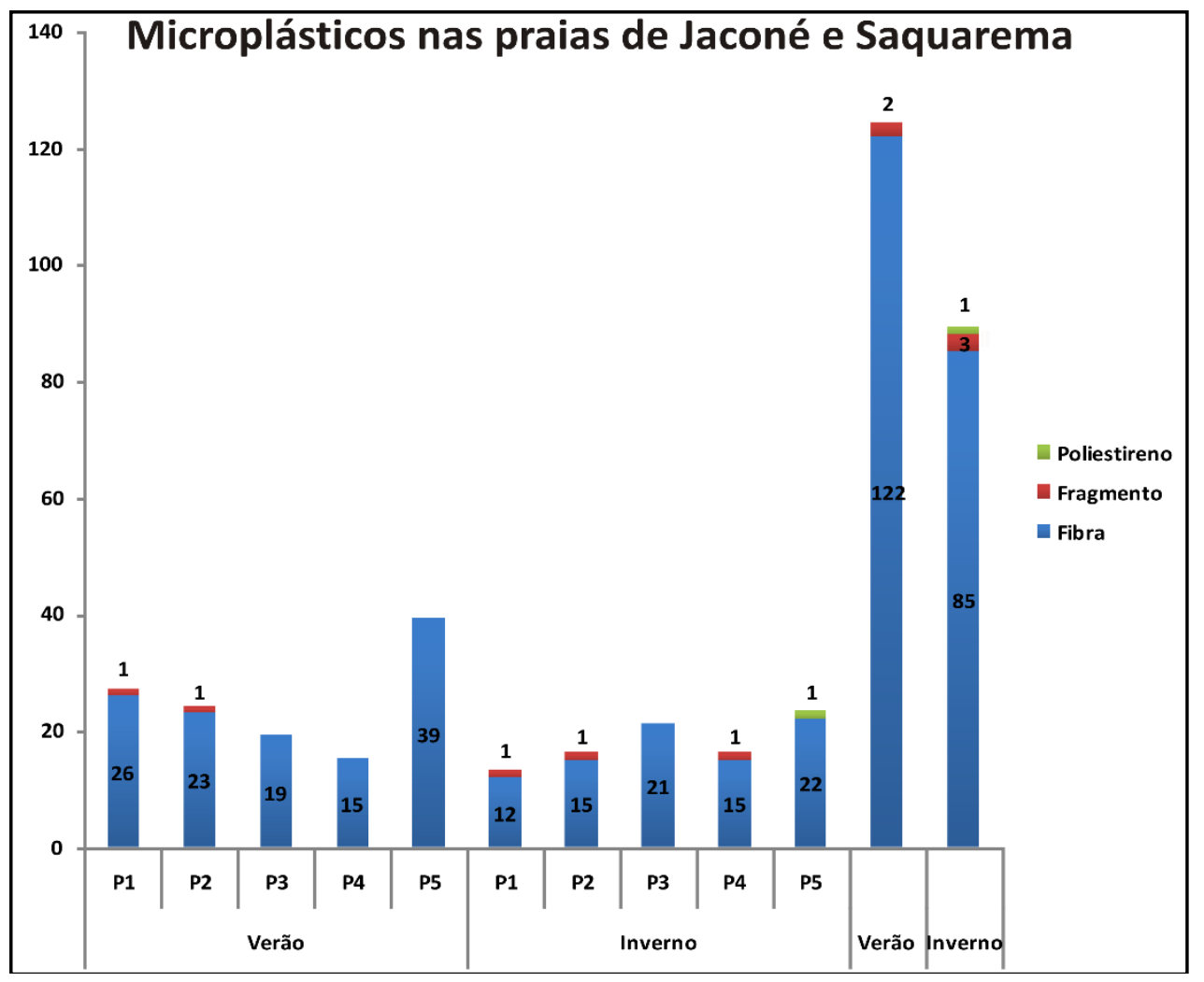

Figura 6 - Quantidade e tipo de microplásticos identificados nas praias de JaconéSaquarema ao longo dos locais de monitoramento e entre o verão e inverno de 2018. 


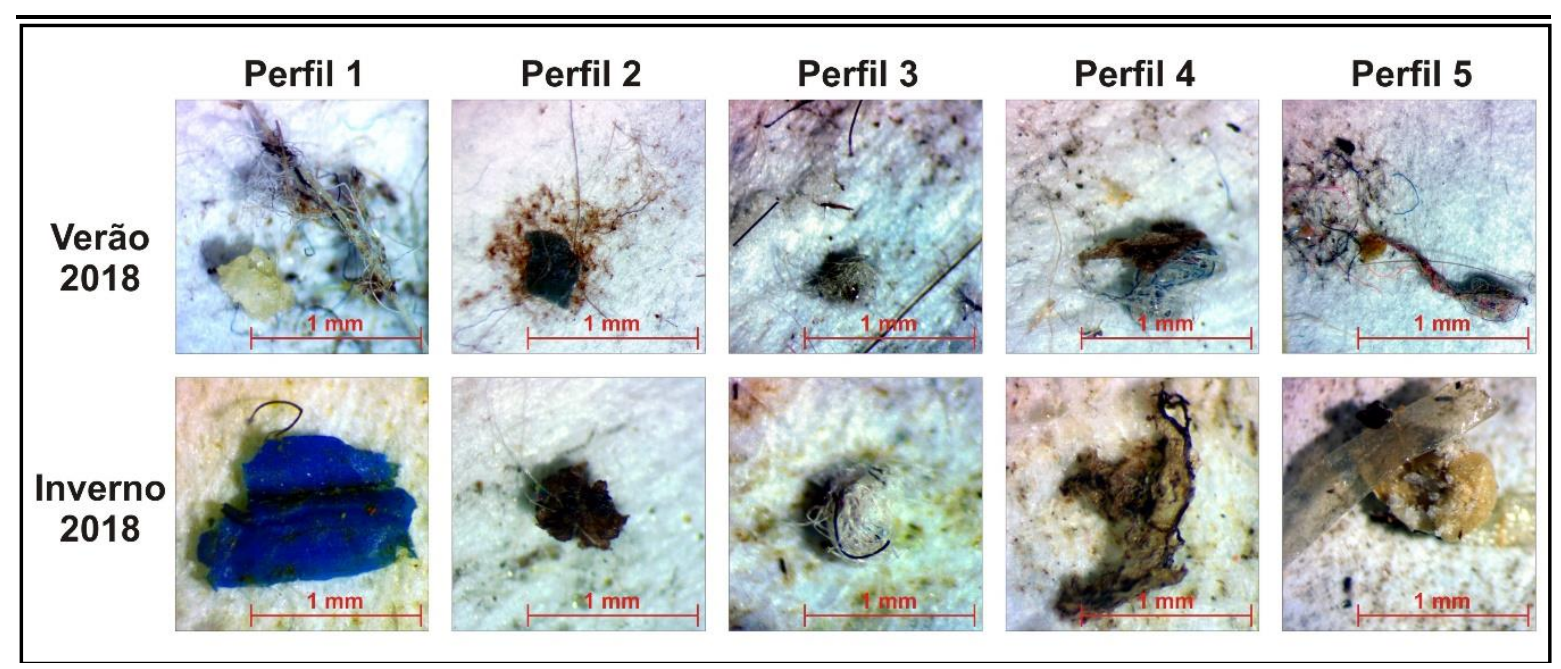

Figura 7 - Microplásticos identificados no arco praial de Jaconé-Saquarema nas estações do verão e inverno de 2018.

\section{Discussão}

Os resultados mostram uma maior concentração de resíduos sólidos no setor oeste (área menos urbanizada) no verão, diminuindo em direção a leste (área mais urbanizada); contrastando com os resultados obtidos no inverno de 2018 (Figura 8). Durante o verão, as variações na largura da praia são menores como resultado da predominância de condições de mar calmo e com ondulações com altura inferior a 1 metro na arrebentação (PINTO, 2018). Essas condições, marcadas por uma maior estabilidade do perfil praial, tendem a contribuir para um maior tempo de permanência de resíduos sólidos no pós-praia; que em geral é alcançado somente pelas grandes ondas de tempestades (CARTER, 1988; DAVIS Jr e FITZGERALD, 2004). Os processos costeiros também podem contribuir para a deposição de resíduos sólidos ao longo do arco praial. O maior acúmulo de materiais distintos e de tamanhos variados no setor oeste durante o verão pode estar relacionado à corrente de deriva litorânea que, segundo Pinto (2018), tendem a se deslocar preferencialmente para oeste, em resposta a incidência de ondas provenientes de sudeste e sob condição de tempo bom (Figura 8). Autores como Muehe e Corrêa (1989), Santos et al. (2004b), Silva et al. (2008a), Linsde-Barros e Muehe (2010), Oliveira e Muehe (2013), Faria (2014), Silva et al. (2014c) e Linsde-Barros (2017) apontam para o importante papel da corrente de deriva litorânea na costa leste do Estado do Rio de Janeiro. Esse comportamento apresentado pela corrente de deriva litorânea se modifica no inverno, quando ondas de tempestade incidem de sul e, principalmente de sudoeste, proporcionando uma mudança de direção para leste (SILVA et al., 2008a; PINTO, 2018), podendo também estar relacionada com o aumento de resíduos no extremo leste durante esta estação.

Diferente do que normalmente ocorre no verão, a maior incidência de ondas de tempestade no inverno gera maior variabilidade na largura da faixa de areia emersa (PINTO, 2018), podendo ser responsável pelo retrabalhamento e desgaste dos materiais ao longo do arco praial, além de remobilizar os resíduos sólidos e disponibilizá-los para o ambiente marinho. Grandes ondas de tempestades também podem ultrapassar o limite interno da praia e alcançar a vegetação de restinga, através do processo de transposição de ondas (overwash), conforme Davis e Fitzgerald (2004). No litoral de Maricá, esse fenômeno tende a formar um 
depósito de sedimentos sobre e na retaguarda da barreira arenosa holocênica, conhecidos como depósitos de leques de arrombamento ou de transposição (SILVA et al., 2008b; PINTO, 2018). A transposição de ondas, somada a influência da maré, tende a misturar os materiais deixados na praia e sobre a vegetação de restinga com aqueles provenientes do mar, dificultando a identificação das principais fontes de resíduos sólidos presentes no ambiente praial. A influência da dinâmica da praia e dos processos costeiros deve ser analisada em conjunto com os diferentes usos entre as estações do ano e ao longo do arco praial. O maior acúmulo de lixo no setor leste durante o inverno (Figura 8) pode estar relacionado também com a redução da limpeza no pós-praia nesta estação, devido à diminuição da frequência de banhistas. Restos de materiais usados na construção civil também foram identificados ao longo do arco praial, podendo estar associados ao descarte irregular feito por moradores. O crescimento urbano na região tem ocorrido de forma intensa (HERCULANO, 1981), principalmente na parte central e leste do litoral estudado. A destruição de estruturas urbanísticas na área por ressacas também pode estar contribuindo com materiais diversos para a praia. Esse litoral possui um histórico de problemas associados à destruição de estrturas urbanas (estrada, quiosques, postes, calçadão, etc.) e por fortes ondas de tempestade (PINTO, 2018). 


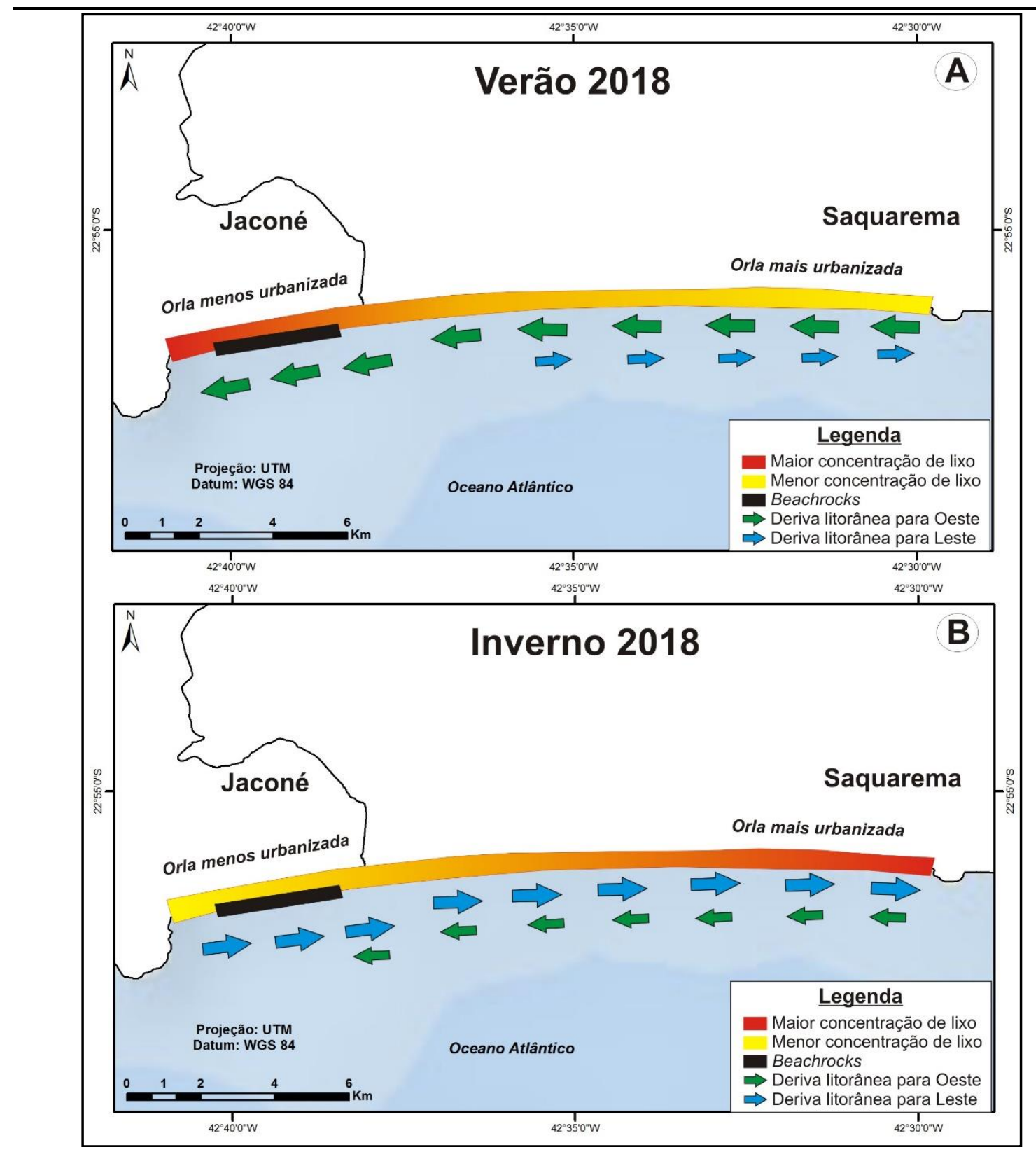

Figura 8 - Comportamento dos resíduos sólidos no arco praial de Jaconé-Saquarema.

O plástico é o tipo de resíduo sólido predominante em todo o arco praial, representando $75 \%$ dos materiais encontrados (Tabela 1 e Figura 3). Este tipo de material tende a promover danos aos ecossistemas costeiros e marinhos (SANTOS et al., 2008). De acordo com Cozár et al. (2014) por se tratar de um material leve, seu transporte por correntes oceânicas pode ocorrer por longas distâncias, alcançando até mesmo algumas ilhas remotas no Pacífico Sul. Em ambiente natural, o plástico possui um lento tempo de degradação, podendo permanecer na natureza por séculos. Os resultados obtidos neste estudo corroboram com outros encontrados em diferentes áreas no litoral do Brasil (ARAÚJO, 2003; SANTOS et al., 2004a; CALDAS, 2007; SOARES et al., 2007; MACEDO et al., 2017; MADUREIRA et al., 2017; PIANOWSKI et al., 1998) e do mundo (DERRAIK, 2002; COLE et al., 2011), onde o plástico também se destaca como material mais abundante quando comparado aos 
demais resíduos sólidos. Este cenário resulta de um crescente descarte irregular, em resposta ao aumento na produção ao longo das últimas décadas (GEYER et al., 2017). O descarte inadequado de alguns materiais, como seringas e agulhas, oferece risco à saúde dos usuários da praia. Materiais semelhantes foram encontrados também na praia do Abraão (Ilha Grande, RJ) por Macedo et al. (2017).

Grande parte dos resíduos sólidos encontrados parecem ter sido transportados pelo mar, como brinquedos, garrafas de óleo, carvão, entre outros (Tabela 1 e Figura 4). Esses resíduos podem ter sido depositados na linha de deixa formada por ocasião da preamar. Os materiais identificados apresentaram um elevado grau de degradação, principalmente no verão, possivelmente devido (1) ao tempo de permanência no ambiente praial e a exposição aos processos subaéreos (chuva, insolação, vento, etc.); e (2) ao retrabalhamento sofrido pela dinâmica de ondas, principalmente sob condição de alta energia, quando estas tendem a alcançar toda extensão da praia, conforme verificado em Itaipuaçu por Rosa e Silva (2016).

A poluição por microplásticos vem sendo observada em diversas partes do litoral brasileiro (IVAR DO SUL e COSTA, 2007; SANTOS et al., 2008; COSTA et al., 2010; FISNER et al., 2013; CARVALHO e BAPTISTA NETO, 2016). Carvalho e Baptista Neto (2016) identificaram altas concentrações de microplásticos nos sedimentos das praias e no fundo da Baía de Guanabara, demonstrando o potencial do ambiente ao acúmulo destes poluentes. Trata-se de um comportamento semelhante ao que vem sendo observado a nível global em termos de poluição por microplásticos (CORCORAN et al., 2009; CLAESSENS et al., 2011; COLE et al., 2011; CARVALHO e BAPTISTA NETO, 2016; HINATA et al., 2017). A maioria das pesquisas dessa natureza aponta que as micropartículas de plásticos se encontram difundidas por diversos ambientes ao longo da costa brasileira e do mundo.

A análise do conteúdo de micropartículas de plástico nos sedimentos superficiais da praia permitiu verificar a presença destes materiais em meio aos grãos de areia em cada setor dos ambientes praiais estudados (Tabela 2, Figuras 6 e 7). Entre as micropartículas de plástico encontradas estão principalmente as do tipo fibra e, em menor quantidade, fragmentos e poliestireno (isopor); pellets não foram identificados nas areias das praias estudadas (Tabela 2, Figuras 6 e 7). Estes pequenos resíduos podem chegar ao oceano através da lavagem doméstica de diferentes tipos de tecido (CESA, 2017), ou são gerados no próprio ambiente aquático, por meio da fotodegradação e pela degradação mecânica. Segundo Browne et al. (2007) a incidência de ondas e abrasão por sedimentos, também contribuem para o retrabalhamento dos microplásticos, tornando-os ainda menores, o que não os torna menos degradantes ao meio ambiente. As fibras evidenciam usos relacionados à pesca e a eventuais atividades esportivas na praia. Este tipo de micro resíduo também foi encontrado na Baía de Guanabara por Carvalho e Baptista Neto (2016) e por Mathalon e Hill (2014) em sedimentos localizados nas zonas de intermaré ao longo da costa leste da Nova Escócia. Apesar das contribuições dadas por diversos autores, o impacto das micropartículas de plásticos em ambientes costeiros ainda é pouco conhecido, o que aumenta a necessidade de novas pesquisas envolvendo um aprofundamento teórico-metodológico e a investigação dos impactos causados por esses materiais em litorais no Brasil e no mundo. Fisner et al. (2013) reforça a necessidade de estudos dessa natureza e chamam a atenção para os impactos sobre o ecossistema costeiro e marinho referente a contaminação por diferentes tipos de microplásticos e suas toxidades. 


\section{Conclusão}

No total foram encontrados 2500 itens nas estações de verão e inverno de 2018; dos quais 1876 (75\%) são compostos por materiais plásticos, evidenciando a predominância deste tipo de material devido a sua ampla utilização e a sua maior durabilidade no meio ambiente. Os materiais encontrados nas praias estudadas exibem um elevado grau de alteração relacionado ao desgaste promovido pela ação das ondas. Diferente do que foi observado no verão, os materiais encontrados no inverno se apresentaram relativamente menos desgastados, o que sugere um baixo tempo de permanência no ambiente.

No verão, a menor concentração de resíduos sólidos no setor leste (Saquarema) foi acompanhada de um aumento gradual para oeste (Jaconé), possivelmente devido à influência da corrente de deriva litorânea predominando nessa direção em resposta à incidência de ondas de tempo bom provenientes de sudeste; além da quase total ausência de limpeza em boa parte da praia de Jaconé. No inverno, a concentração dos resíduos sólidos apresentou um aumento em direção ao setor leste (Saquarema), e pode ser o resultado da redução da coleta de materiais nessa estação, associada à chegada de uma maior quantidade de resíduos sólidos pelo mar, num momento em que as ondas tendem a alcançar com mais frequência toda a extensão da faixa de areia da praia.

Os microplásticos observados na área de estudo, representados na sua quase totalidade por fibras, podem estar relacionadas à atividade pesqueira e a prática de esportes na faixa de areia da praia. Essas micropartículas são capazes de transportar microrganismos por variadas distâncias, podendo prejudicar a fauna marinha e costeira, além de representar um risco à saúde humana.

Os problemas ocasionados pelo descarte irregular de resíduos sólidos no litoral de Jaconé-Saquarema são evidentes e tendem a se agravar em virtude do aumento populacional e das atividades relacionadas ao turismo. Diante disso, é importante a conscientização quanto à necessidade de se adotar de medidas voltadas para a preservação dos ecossistemas costeiros e marinhos. Logo, faz-se necessário uma maior atenção quanto às questões que envolvem o descarte e o tratamento de resíduos sólidos em diferentes escalas.

\section{Referências bibliográficas}

ARAÚJO, M. C. B. Resíduos sólidos em praias do litoral sul de Pernambuco: origens e consequências. Dissertação (Mestrado) - Departamento de Oceanografia, Universidade Federal de Pernambuco, Pernambuco, Brasil. p. 31-56, 2003.

BAPTISTA NETO, J. A. B.; DA FONSECA, E. M. Seasonal, spatial and compositional variation of beach debris along of the eastern margin of Guanabara Bay (Rio de Janeiro) in the period of 1999-2008. Journal of Integrated Coastal Zone Management, v. 11, p. 3139, 2011.

BARNES, D. K. A. Invasions by marine life on plastic debris. Nature, v.416, p. 808-809, 2002.

BESLEY, A.; VIJVER, M. G.; BEHRENS, P.; BOSKER, T. A standardized method for sampling and extraction methods for quantifying microplastics in beach sand. Marine Pollution Bulletin, v.114, p. 77-83, 2016. 
BIAZZI, F. M.; TONELLO, D. Relatório de Impacto Ambiental (RIMA) Terminal de Ponta Negra (TPN). ARCADIS logos. 88 p, 2014.

BROWNE, M. A.; GALlOWAY, T.; THOMPASON, R. Microplastic - an emerging contaminant of potential concern? Integrated Environmental Assessment and Management, v.3, p. 559-561, 2007.

CALDAS, A. H. M. Análise da disposição de resíduos sólidos e da percepção dos usuários em áreas costeiras - um potencial de degradação ambiental. (Trabalho de Conclusão de curso). Departamento de Engenharia Ambiental. Universidade Federal da Bahia, Salvador, Brasil. p. 33-54, 2007.

CARTER, R. W. G. Coastal Environments: An Introduction to the Physical, Ecological and Cultural Systems of Coastlines. London: Academic Press, 617p, 1988.

CARVALHO, D. G.; BAPTISTA NETO, J. A. Microplastic pollution of the beaches of Guanabara Bay Southeast Brazil. Ocean \& Coastal Management, v.128, p. 10-17, 2016.

CESA, F. S. Microplásticos têxteis: emissão de fibra sintética na lavagem domestica. Dissertação (Mestrado) - Universidade de São Paulo. Escola de Artes, Ciências e Humanidades. 156p, 2017.

CLAESSENS, M.; MEESTER, S. D.; LANDUYT, L. V.; CLERCK, K. D.; JANSSEN, C. $\mathrm{R}$. Occurrence and distribution of microplastics in marine sediments along the Belgian coast. Marine Pollution Bulletin, v.62, p. 2199-2204. 2011.

COE, J. M.; ANDERSSON, S.; ROGERS, D. B. Marine debris in the Caribbean Region. In: COE, J.M., ROGERS, D.B. Eds., Marine Debris: Sources, Impacts and Solutions. Springer, New York, p. 25-34, 1997.

COE NETO, R.; FROIDEFOND, J. M.; TURCQ, B. Geomorphologie et chronologie relative des depots sedimentaires recents du littoral bresilien a l'est de Rio de Janeiro. Bulletin de l'Institut de Geólogie du Bassin d'Aquitaine, Bourdeaux, n. 40, p. 67-83, 1986.

COLE, M.; LINDEQUE, P.; HALSBAND, C.; GALlOWAY, T. S. Microplastics as contaminants in the marine environment: A review. Marine Pollution Bulletin, v.62, p. 2588-2597, 2011.

CONCREMAT. Projeto básico para a fixação da barra franca de Saquarema. 2011.

CORCORAN, P. L.; BIESINGER, M. C.; GRIFI, M. Plastics and beaches: a degrading relationship. Marine Pollution Bulletin, v.58, p. 80-84, 2009.

COSTA, E.; DOS SANTOS, A.; SEABRA, V. Uso de mapa geomorfológico para mapeamento de uso e cobertura da terra no município de Maricá - RJ. In: XI SINAGEO Geomorfologia: compartimentação de paisagem, processo e dinâmica. Anais. Maringá, PR, 2016.

COSTA, M. F.; IVAR DO SUL, J. A.; SILVA-CAVALCANTI, J. S.; ARAÚJO, M. C. B.; SPENGLER, A.; TOURINHO, P. S. On the importance of size of plastic fragments and pellets on the strandline: a snapshot of a Brazilian beach. Environmental Monitoring and Assessment, v.168, p. 299-304, 2010. 
CÓZAR, A.; ECHEVARRÍA, F.; GONZÁLEZ-GORDILLO, J. I.; IRIGOIEN, X.; ÚBEDA, B.; HERMÁNDEZ-LEÓN, S.; PALMA, Á. T.; NAVARRO, S.; GARCÍA-DE-LOMAS, J.; RUIZ, A.; FERNÁNDES-DE-PUELLES, M. L. Plastic debris in the open ocean. Proceedings of the National Academy of Sciences, v.111 (28): 10239-10244, 2014.

DAVIS, JR. A. R.; FITZGERALD, D. M. Beaches and Coasts. United Kingdom: Blackwell Publishing, 2004.

DERRAIK, J. G. B. The pollution of the marine environment by plastic debris: a review. Marine Pollution Bulletin, v,44. (9): 842-852. DOI: 10.1016/S0025-326X(02)00220-5, 2002.

DOS SANTOS, A. A. B.; COSTA, E. C. P.; SOUSA, R. C. S.; SEABRA, V. S. Aplicação ambiental em geoprocessamento: análise das mudanças de uso e cobertura da terra no município de Saquarema-RJ nos anos de 1984 e 2014. In: V Simpósio de Gestão Ambiental e Biodiversidade. Anais. Três Rios, RJ, 2016.

FARIAS, C. R. S. M.; JARDIM, T. D. M. Rio+20: oceanos, mares e zonas costeiras. [Boletim Legislativo, n. 17 Brasília: Senado Federal] 2012, 6 p. Disponível em: \&amp;lt;http://www12.senado.leg.br/publicacoes/estudos-legislativos/tipos-de-

estudos/outras-68 publicações/tema-se- agendas-para- o-desenvolvimento- sustentável/rio20- oceanos-mares- e- zonas-costeiras \&amp; gt; Acessado em: (09/07/2016), 2012.

FARIA, C. S. Dinâmica sazonal da praia e vulnerabilidade do litoral de Saquarema (RJ) às ondas de tempestades. (Monografia) - Curso de Especialização em Dinâmicas Urbanoambientais e Gestão do Território da UERJ-FFP. p. 66-70, 2014.

FISNER, M.; TANIGUCHI, S.; MOREIRA, F.; BÍCEGO, M. C.; TURRA, A. Polycyclic aromatic hydrocarbons (PAHs) in plastic pellets: variability in the concentration and composition at different sediment depths in a sandy beach. Marine Pollution Bulletin, v.70, p. 219- 226, 2013.

GEYER, R.; JAMBECK, J. R.; LAW, K. L. Production, use and fate of all plastics ever made. Science (Advances), v. 3. (7): DOI: 10.1126/sciadv.1700782, 2017.

GREGORY, M. R. Plastic pellets on New Zealand beaches. Marine Pollution Bulletin, v.9. p, 82-84, 1997.

HERCULANO, S. Saquarema: história de sua urbanização pela função-veraneio e a disputa por suas terras públicas (1955-1980): analisando um caso de desenvolvimento local na Região dos Lagos (RJ). Artigo feito com base na dissertação de Mestrado em Planejamento Urbano e Regional intitulada "A cidade sazonal: a urbanização pela função-veraneio e pela privatização de terras públicas - um estudo de caso de Saquarema (RJ), 14 p, 1981.

HINATA, H.; MORIA, K.; OHANOA, K.; MIYAOA, Y.; KATAOKA, T. An estimation of the average residence times and onshore-offshore diffusivities of beached micro-plastics based on the population decay of tagged meso- and macrolitter. Marine Pollution Bulletin, v.122, p.17-26, 2017. 
IRELAND, S. The Holocene Sedimentary History of the Coastal Lagoons of Rio de Janeiro State, Brazil. In: Sea Level Changes. TOOLEY, M.; SHENNAM, I. (eds.). Oxford: Brazil Blackwell Ltd. p. 25-66, 1987.

IVAR DO SUL, J. A.; COSTA, M . F. Marine debris review for Latin America and the Wider Caribbean Region: from the 1970s until now, and where do we go from here? Marine Pollution Bulletin, v.54, 1087-1104, 2007.

LAIST, D. W. Overview of the biological effects of lost and discarded plastic debris in the marine environment. Marine Pollution Bulletin, v.18. (6B): p. 319-326, 1987.

LAIST, D. W. Impacts of marine debris: entanglement of marine life in marine debris including a comprehensive list of species with entanglement and ingestion records. In: Coe, J., Rogers, D. B. (Eds.) Marine Debris: Sources, Impacts and Solutions. Springer Series on Environmental Management, New York, USA, p. 99-119, 1997.

LINS-DE-BARROS, F. M. \& MUEHE, D. Avaliação local da vulnerabilidade e riscos de inundação na zona costeira da Região dos Lagos, Rio de Janeiro. Quaternary and Environmental Geosciences, ano 2, n.1, pp. 55-66, 2010.

LINS-DE-BARROS, F. M. Integrated coastal vulnerability assessment: A methodology for coastal cities management integrating socioeconomic, physical and environmental dimensions-Case study of Região dos Lagos, Rio de Janeiro, Brazil. Ocean Coast. Management, v.149, p. 1-11, 2017.

MACEDO, A. V.; SIlVA, A. L. C.; MADUREIRA, E. A. L. M.; SILVESTRE, C. P. Poluição por lixo nas praias de Abraão e Preta na borda setentrional-oriental da Ilha Grande (Angra dos Reis, RJ) e o impacto sócio-ambiental In: Simpósio Brasileiro de Geografia Física Aplicada - Os desafios da Geografia Física na Fronteira do conhecimento, 17. Anais. São Paulo: UNICAMP, v.1, p. 3009-3014, 2017.

MADUREIRA, E.; SILVA, A. L. C.; MACEDO, A.V.; GRALATO, J. C. A. Análise da composição, distribuição e origem do lixo nas praias oceânicas de Dois Rios e Lopes Mendes na Ilha Grande (Angra dos Reis, RJ). In: Simpósio Brasileiro de Geografia Física Aplicada - Os desafios da Geografia Física na Fronteira do conhecimento, 17. Anais. São Paulo: UNICAMP, v.1, p. 3015-3020, 2017.

MAIA, M. C. A. C.; MARTIN, L.; FLEXOR, J. M. Evolução Holocênica da planície costeira de Jacarepaguá (RJ). In: XXXIII Congresso Brasileiro de Geologia, Rio de Janeiro, p. 105$118,1984$.

MANSUR, K. L.; RAMOS, R. R. C.; GODOY, J. M. O.; NASCIMENTO, V. M. R. Beachrock de Jaconé, Maricá e Saquarema - RJ: importância para a história da ciência e para o conhecimento geológico. In: Revista Brasileira de Geociências, v.41. (2): 290-303, 2011.

MATHALON, A.; HILL, P. Microplastic fibers in the intertidal ecosystem surrounding Halifax Harbor, Nova Scotia. Marine Pollution Bulletin, 2014.

MUEHE, D.; CORRÊA, C. H. T. Dinâmica de praia e transporte de sedimentos na restinga de Massambaba. Revista Brasileira de Geociências, v.19, n.3, p. 387-392, 1989. 
$\overline{\text { OLIVEIRA, J. F. DE.; MUEHE, D. Identificação das áreas de sedimentos compatíveis na }}$ plataforma continental interna para recuperação de praias entre as cidades de Niterói e Macaé - Rio de Janeiro, Brasil. Revista da Gestão Costeira Integrada, v.13, n.1, pp. 89-99, 2013.

PEREIRA, A. J.; GAMBOA, L. A. P.; SILVA, M. A. M.; RODRIGUES, A. R.; COSTA, A. A Utilização do Ground Penetraiting Radar (GPR) em Estudos de Estratigrafia na Praia de Itaipuaçú - Maricá (RJ). In: Revista Brasileira de Geofísica. Niterói: EDUFF, v. 21, n.2, p. 163-171, 2003.

PERRIN, P. Evolução da Costa Fluminense entre as Pontas de Itacoatiara e Negra, preenchimentos e restingas. In: Restingas, origens, processos. Lacerda, L. D., Araújo, D. S. D., Cerqueira, R.; Turcq, B. (Eds). CEUFF, Niterói. p. 65-74, 1984.

PIANOWSKI, F.; SILVA, K G.; FILLMANN, G. Resíduos sólidos e esférulas plásticas no litoral do Rio Grande do Sul - Brasil. XI Semana Nacional de Oceanografia, Rio Grande. XI Semana Nacional da Oceanografia: Oceanografia e suas interfaces - Resumo expandido. Pelotas: Editora Universitária - UFPEL, 1998, v.1, p. 547-549, 1998.

PINTO, V. C. S.; SILVA, A. L. C.; SILVESTRE, C. P.; ANTONIO, R. V. M. Ambiente praial e a influência do arenito de praia na distribuição dos sedimentos em Jaconé (Maricá, RJ). Anais do XVI Simpósio Brasileiro de Geografia Física Aplicada - 116 Territórios Brasileiros: Dinâmicas, Potencialidades e Vulnerabilidades. Teresina, Piauí, v.1. ISSN: 2236-5311, 2015.

PINTO, V. C. Caracterização morfológica e sedimentar da planície costeira e vulnerabilidade do litoral de Jaconé-Saquarema $(R J)$ às ondas de tempestade. Dissertação (Mestrado) - Universidade do Estado do Rio de Janeiro. Faculdade de Formação de Professores. Departamento de Geografia. 135p, 2018.

PRUTER, A. T. Sources, quantities and distribuition of persistent plastics in the marine environment. Marine Pollution Bulletin, v.18. (6B): 305-310, 1987.

ROSA, K. S.; SILVA, A. L. C. A influência dos processos costeiros na origem e distribuição do lixo na praia de Itaipuaçu (Maricá, RJ). XI SINAGEO. Anais. Maringá, PR, 2016.

RYAN, P. G.; MOORE, C. J.; VAN FRANEKER, J. A.; MOLONEY, C. L. Monitoring the abundance of plastic debris in the marine environment. Philosophical Transactions of the Royal Society B: Biological Sciences, v. 364, p. 1999-2012, 2009.

SANTOS, A. S. F.; AGNELLI, J. M., MANRICH, S. Tendências e desafios da reciclagem de embalagens plásticas. Polímeros - Ciência e Tecnologia, v. 4, n. 5, 2004a.

SANTOS, C. L. DOS.; SILVA, M. A. M. DA.; SALVADOR, M. V. S. Dinâmica sazonal e os efeitos das ressacas nas praias de Niterói/RJ. Revista Brasileira de Geociências, v.34, n.3, p. 355-360, 2004b.

SANTOS, I. R.; BAPTISTA NETO, J. A.; WALLNER-KERSANACH, M. Resíduos Sólidos. In: BAPTISTA NETO, J. A., WALLNER-KERSANACH, M., PATCHINEELAM, S. M. (Coordenadores). Poluição marinha. Interciência, Rio de Janeiro. p. 309-330, 2008. 
SANTOS, I. R.; FRIEDRICH, A. C.; IVAR DO SUL, J. A. Marine debris contamination along undeveloped tropical beaches from northeast Brazil. Environmental Monitoring and Assessment, v.148. (1-4). p. 455-462. DOI: 10.1007/s10661-008-0175-z, 2009.

SILVA, A. L. C.; SILVA, M. A. M.; SANTOS, C. L.; RIBEIRO, G. B.; SANTOS, R. A. \& VASCONCELOS, S. C. Retrogradação da Barreira Arenosa e Formação de Leques de Arrombamento na Praia de Itaipuaçu (Oeste de Maricá, RJ). Revista Brasileira de Geomorfologia, ano 9, n.2, pp. 75-82, 2008a.

SILVA, A. L. C.; SILVA, M. A. M.; SANTOS, C. L. Comportamento morfológico e sedimentar da praia de Itaipuaçu (Maricá, RJ) nas últimas três décadas. Revista Brasileira de Geociências, v. 38, n.1, pp. 89-99, 2008b.

SILVA, A. L. C. Arquitetura sedimentar e evolução geológica da planície costeira central de maricá (RJ) ao longo do Quaternário. $185 \mathrm{f}$. Tese (Doutorado) em Geologia e Geofísica Marinha - Departamento de Geologia, Universidade Federal Fluminense, Niterói, Rio de Janeiro, 2011.

SILVA, A. L. C.; SILVA, M. A. M.; SOUZA, R. S.; PINTO, M. L. V. The role of beachrocks on the evolution of the Holocene barrier systems in Rio de Janeiro, southeastern Brazil. In: Green, A.N. and Cooper, J.A.G. (eds.), Proceedings 13th International Coastal Symposium (Durban, South Africa), Journal of Coastal Research, Special Issue, n. 70, p. 170-175, $2014 \mathrm{a}$.

SILVA, A. L. C.; SILVA, M. A. M.; GAMBOA, L. A. P.; RODRIGUES, A. R. Sedimentary architecture and depositional evolution of the Quaternary coastal plain of Maricá, Rio de Janeiro, Brazil. Brazilian Journal of Geology, v.44, n. 2, p. 191-206, 2014b.

SILVA, A. L. C.; SILVA, M. A. M.; GRALATO, J. C. A.; SILVESTRE, C. P. Caracterização geomorfológica e sedimentar da planície costeira de Maricá (Rio de Janeiro). Revista Brasileira de Geomorfologia, v.15. (2). 231-249, 2014c.

SIlveSTRE, C. P.; SIlVA, A. L. C.; SIlvA, M. A. M.; BAPTISTA NETO, J. A.; VASCONCELOS, S. C. Geomorfologia, sedimentação e processos atuantes na Lagoa de Maricá, Rio de Janeiro. Revista Brasileira de Geomorfologia, v. 18, p. 237-256, 2017.

SOARES, A. M.; COSTA, M.; SILVA, J. S.; ARAÚJO, M. C. B. - Contaminação da linhado-deixa da praia da Boa Viagem (Recife-PE) por resíduos sólidos no verão de 2005: uma nova metodologia de avaliação. XII Congresso Latino-Americano de Ciências do Mar XII COLACMAR, Florianópolis, SC, Brasil, 2007.

SOMERVILLE, S. E.; MILLER, K. L.; MAIR, J. M. Assessment of the aesthetic quality of a selection of beaches in the Firth of Forth, Scotland. Marine Pollution Bulletin, v.46, p. 1184-1190, 2003.

THOMPSON, R. C.; OLSEN, Y.; MITCHELL, R. P.; DAVIS, A.; ROWLAND, S. J.; JOHN, A. W. G.; MCGONIGLE, D.; RUSSELL, A. E. Lost at Sea: where is all the plastic? Science, v.304, p.838, 2004.

TURCQ, B.; MARTIN, L.; FLEXOR, J. M.; SUGUIO, K.; PIERRE, C.; TASAYACOORTEGA, L. Origin and Evolution of the Quaternary Coastal Plain between Guaratiba and 
Cabo Frio, State of Rio de Janeiro, Brazil. Environmental Geochemistry of Coastal

Lagoon Systems. Rio de Janeiro, Brazil - série Geoquímica Ambiental, v.6, p. 25-46, 1999.

UNEP. (United Nations Environment Programme). Marine Litter, na analytical overview. Nairob: United Nations Enviroment Programme, p.58, 2005. 